\title{
PRIVATIZAÇÃO: BOM OU RUIM? LIÇÕES DO SETOR DE DISTRIBUUIÇÃO DE ENERGIA ELẺTRICA DO NORDESTE BRASILEIRO
}

PRIVATIZATION: GOOD OR BAD? LESSONS FROM THE ELECTRICITY DISTRIBUTION SECTOR IN THE NORTHEAST OF BRAZIL

PRIVATIZACIÓN: ¿BUENA O MALA? LECCIONES DEL SECTOR DE DISTRIBUCIÓN DE ENERGÍA ELÉCTRICA DEL NORESTE BRASILEÑO

\section{RESUMO}

Este trabalho analisa a evolução de cinco distribuidoras de energia elétrica, localizadas no Nordeste do Brasil, por meio de indicadores técnicos e financeiros. Três empresas privatizadas e duas públicas foram analisadas entre 1997 e 2008 . Os indicadores financeiros mostram a lucratividade e capacidade de as firmas gerarem valor para os acionistas, enquanto os técnicos a qualidade do serviço prestado aos consumidores. Duas proposições foram estabelecidas sugerindo que as empresas privatizadas tiveram seus indicadores financeiros e técnicos melhorados, comparativamente às empresas públicas, depois da privatização. Observou-se que os indicadores financeiros das distribuidoras privatizadas melhoraram em relação aos das públicas, gerando mais valor para seus acionistas. No entanto, não há evidência de que a privatização impactou na melhoria dos indicadores técnicos e qualidade do serviço.

PALAVRAS-CHAVE Empresas de distribuição de energia elétrica, setor elétrico, energia elétrica, privatização, política energética.

Bruno dos Santos Silvestre bruno_silvestre@sfu.ca

Professor da Faculty of Business Administration, Simon Fraser University - Burnaby - BC, Canadá

Jeremy Hall jeremy_hall@sfu.ca

Professor da Faculty of Business Administration, Simon Fraser University - Burnaby - BC, Canadá

Stelvia Matos smatos@sfu.ca

Professora da Faculty of Business Administration, Simon Fraser University - Burnaby - BC, Canadá

Luiz Augusto Pereira de Andrade Figueira lapaf@uol.com.br

Superintendente das Centrais Elétricas Brasileira - Rio de Janeiro - RJ, Brasil

Recebido em 30.10.2008. Aprovado em 21.12.2009

Avaliado pelo sistema double blind review. Editora Científica: Carmem Augusta Varela

ABSTRACT This paper analyzes the evolution of five electricity distribution companies in the Northeast of Brazil using technical and financial indexes. Three privatized and two public firms were analyzed between 1997 and 2008. The financial indexes are related to the profitability and firm's capacity of generating value for its shareholders, while the technical indexes are related to the quality of the service provided. Two propositions are developed suggesting that privatized firms had their financial and technical indexes improved after privatization when compared to the public firms. We observed the privatized firms had their financial indexes improved after the privatization, increasing their value for the shareholders. However, it was not possible to observe evidence that privatization affected the quality of service provided.

KEYWORDS Electricity distribution companies, electricity sector, electric energy, privatization, energy policy.

RESUMEN Este trabajo analiza la evolución de cinco empresas distribuidoras de energía eléctrica ubicadas en el Noreste de Brasil, por medio de indicadores técnicos y financieros. Tres empresas privatizadas y dos públicas fueron analizadas entre 1997 y 2008. Los indicadores financieros muestran la lucratividad y la capacidad de las empresas de generar valor para los accionistas, y los indicadores técnicos muestran la calidad del servicio prestado. Se establecieron dos proposiciones sugiriendo que los indicadores financieros y técnicos de las empresas privatizadas fueron mejorados después de la privatización, comparativamente a las empresas públicas. Se observo que los indicadores financieros de las distribuidoras privatizadas mejoraron en relación a los de las públicas, generando más valor para SUS accionistas. No obstante, no existe evidencia de que la privatización haya tenido impacto sobre la mejora de los indicadores técnicos y la calidad del servicio prestado.

PALAVRAS CLAVE Empresas de distribución de energía eléctrica, sector eléctrico, energía eléctrica, privatización, politica energética. 


\section{INTRODUÇÃO}

No final do século XIX, as empresas de distribuição de energia elétrica foram estruturadas sob a forma de monopólios e passaram a ser reguladas com o objetivo de se evitar exploração monopolista dos consumidores, resguardando, contudo, uma remuneração adequada para os investidores (REIS e outros, 2007).

Apesar da importância estratégica, o setor elétrico brasileiro somente se transformou em uma das prioridades, juntamente com os esforços de industrialização que ocorreram no país. No governo JK, por exemplo, a partir do Plano de Metas (1956-61), houve grande incentivo ao setor, como forma de alcançar a modernização. Nessa época, havia uma ação conjunta entre Estado e empresas privadas, nacionais e estrangeiras, visando à ampliação de operações de crédito para viabilização dos investimentos necessários (GOMES e outros, 2002).

Como parte do esforço nacional, de acordo com Werneck (1997), a Centrais Elétricas Brasileiras S.A. (ELETROBRÁS) foi criada em 1962 com o intuito de promover a coordenação e a administração dos recursos destinados ao setor elétrico. Essa nova organização assumia o lugar ocupado até então pelo Banco Nacional de Desenvolvimento Econômico e Social (BNDES), na coordenação, financiamento e incentivo à expansão e melhoria do sistema elétrico nacional (GOMES e outros, 2002).

Já na década de 1970, houve uma grande expansão da economia, com destaque para a capacidade interna de geração de recursos, o que permitiu o autofinanciamento do setor elétrico, além dos recursos externos que ingressavam na economia brasileira (GOMES e outros, 2002).

Nessa época, o regime tarifário foi unificado, como forma de igualar os preços pagos pelos diversos estados da federação. Antes disso, as regiões menos desenvolvidas apresentavam um custo de energia muito mais elevado e os projetos de investimento se apresentavam muitas vezes financeiramente inviáveis. Assim, o governo instituiu uma tarifa igualitária para todo o país, transferindo recursos de empresas superavitárias para empresas deficitárias, por meio da formação de fundos setoriais geridos pela ELETROBRÁS, tais como a Conta Consumo de Combustível (CCC) e a Reserva Global de Reversão (RGR) (GOMES e outros, 2002; BAHIENSE, 2005).

Durante a década de 1980, a economia brasileira entrou gradualmente em declínio, uma vez que esta era corroída pela alta inflação e por juros elevados. "Com a interrupção dos créditos de organismos internacionais, o setor passou a ter fluxo negativo entre os empréstimos externos e o pagamento do serviço da dívida" (GOMES e outros, 2002, p. 11), o que causou uma profunda crise (GABRIELE, 2004). Nesse período de crise, observa-se o crescimento da inadimplência por parte das concessionárias estaduais, que alegavam que a fixação de tarifas havia prejudicado a obtenção de recursos para investimentos (WERNECK, 1997; GOMES e outros, 2002).

Com o aumento do consumo de energia, no final da década de 1980, aliado aos poucos investimentos realizados no setor, por conta da situação deficitária das contas externas, o fornecimento de eletricidade ficou comprometido, uma vez que não foi possível realizar uma expansão necessária do setor que acompanhasse a expansão da demanda por energia (GOMES e outros, 2002; CARNEIRO, 2002; RIDALVO, 2003). Além disso, o aumento da intensidade de uso de energia elétrica na indústria brasileira, em virtude do processo de modernização (TOLMASQUIM e outros, 2001; FOCACCI, 2005), e do uso residencial (GHISI e outros, 2007), que pode ser comparado em muitos aspectos com os padrões observados em países desenvolvidos como Áustria, Dinamarca, Alemanha, Holanda e Estados Unidos (COHEN e outros, 2005), se tornou um problema difícil de solucionar sem uma ação incisiva de planejamento de longo prazo e investimentos.

Sob esse contexto, o Governo Brasileiro decidiu implementar diversas mudanças no setor elétrico. O processo de privatização das empresas de distribuição de energia elétrica teve início em 1995. Em 1996, foi criada a Agência Nacional de Energia Elétrica (ANEEL), com vistas a monitorar e homogeneizar as atividades do setor (PIRES, 2000; SALGADO, 2003; BAHIENSE, 2005) (para informações detalhadas sobre o processo de reestruturação do setor energético brasileiro, consultar Mendonça e Dahl (1999)). No entanto, as reestruturações no setor elétrico não foram privilégios apenas do Brasil, na medida em que diversos outros países em desenvolvimento implementaram mudanças nesse setor no mesmo período (PARKER e KIRKPATRICK, 2005; CHIRARATTANANON E NIRUKKANAPORN, 2006; ERDOGDU, 2007; CAVALIERE e outros, 2007).

Assim, mesmo diante de discussões, confusão conceitual e indefinições no novo modelo setorial, as privatizações foram implementadas, culminando na privatização de 23 empresas de energia elétrica, dentre as quais 20 são distribuidoras de energia elétrica. Tais privatizações fizeram parte do Programa Nacional de Desestatização (PND), criado em 1991 pelo governo federal, com o intuito de enxugar a máquina pública, como possível forma de reduzir os custos das empresas vendidas e, consequentemente, melhorar suas eficiências (ESPOSITO, 2000; REIS e outros, 2007). Algumas distribuidoras de energia 
elétrica não foram vendidas por falta de interesse da iniciativa privada, ficando sob a gestão da ELETROBRÁS (CARREGARO, 2003). No entanto, mesmo com as mudanças no modelo setorial, a confiança para a realização de novos investimentos foi restabelecida apenas entre 1999-2000 (GOMES e outros, 2002).

Quase duas décadas depois do início do PND e 15 anos após o fim das privatizações, este artigo busca avaliar a evolução de cinco distribuidoras de energia elétrica, por meio de indicadores financeiros e técnicos das empresas de distribuição de energia elétrica, nos períodos anterior e posterior à privatização, comparando-os com outras distribuidoras que ainda continuam sob o controle do Estado. Para isso, duas proposições foram estabelecidas:

Proposição 1 (P1) - as empresas de distribuição de energia elétrica privatizadas tiveram seus indicadores financeiros melhorados - EBITDA (earnings before interests, taxes, depreciation and amortization) e Resultado do Exercício, comparativamente às empresas federais, indicando um aumento do valor dessas empresas para o acionista.

Proposição 2 (P2) - as empresas de distribuição de energia elétrica privatizadas tiveram seus indicadores técnicos melhorados - DEC (Duração Equivalente de Interrupção por Unidade Consumidora) e FEC (Frequência Equivalente de Interrupção por Unidade Consumidora), comparativamente às empresas federais, indicando um aumento da qualidade dos serviços prestados aos consumidores.

Para analisar as proposições estabelecidas, trabalhou-se com uma metodologia que envolveu quatro indicadores distintos, dois financeiros e dois técnicos, aplicada a um grupo de cinco distribuidoras de energia elétrica, sendo duas públicas (Companhia Energética de Alagoas - CEAL e Companhia Energética do Piauí - CEPISA) e três privatizadas no ano de 2000 (Companhia Energética de Pernambuco - CELPE, Companhia Energética do Maranhão - CEMAR e Sociedade Anônima de Eletrificação da Paraíba - SAELPA). Todas as cinco distribuidoras envolvidas nesse estudo possuem suas áreas de concessão localizadas no Nordeste do Brasil.

\section{ANÁLISE DE INDICADORES}

A análise de indicadores é uma técnica bastante utilizada na área de gestão e mais especificamente para a avaliação e valoração de negócios. Para Geisler (2000), um indicador é uma medida reservada para a descrição ou representação de um dado evento ou fenômeno. A OECD (Organization for Economic Co-operation and Development) especifica que os indicadores são compostos por uma série de dados definidos para responder questões sobre um fenômeno ou um sistema particular (OECD, 2001). A FINEP (Financiadora de Estudos e Projetos), organização governamental que avalia e gerencia estudos e projetos e fornece consultoria, utiliza maciçamente os indicadores e entende que eles são as especificações quantitativa e qualitativa para medir o atingimento de um objetivo (FINEP, 2002). A ISO (International Organization for Standardization) estabelece que os indicadores são a expressão (numérica, simbólica ou verbal) empregada para caracterizar as atividades (eventos, objetos, pessoas), em termos quantitativos e qualitativos, com o objetivo de determinar o valor (ISO, 2003).

Em estudos organizacionais, Rozados (2005) conclui que os indicadores nada mais são do que unidades que permitem medir (caso de elementos quantitativos), ou verificar (caso de elementos qualitativos), se estão sendo alcançados os objetivos ou as mudanças previstas. Também possibilitam conhecer melhor os avanços em termos de resultados ou de impactos. Um indicador é, portanto primordialmente, uma ferramenta de mensuração, utilizada para levantar aspectos quantitativos e/ou qualitativos de um dado fenômeno, com vistas à avaliação e a subsidiar a tomada de decisão. Por meio deles, é possível estabelecer a situação em que se encontra uma indústria, um setor, uma empresa ou até mesmo uma área funcional. Os indicadores determinam se a empresa está cumprindo suas metas, sua saúde financeira, operacional e demais aspectos que influenciam o seu desenvolvimento e desempenho.

Para as distribuidoras, os indicadores financeiros tendem a melhorar em função do aumento de sua eficiência operacional, menor quantidade de perdas, menor inadimplência, melhoria dos sistemas de transmissão e distribuição, aumento do número de consumidores regulares (e diminuição dos consumidores taxados a forfait e clandestinos). Já os indicadores técnicos mensuram a qualidade do serviço prestado pelas distribuidoras de energia elétrica aos seus consumidores diretos, que podem ser classificados em residencial, comercial, industrial, rural, poder público e outros. Além disso, a baixa qualidade no serviço gera grandes custos associados, principalmente nas classes de consumo comercial e industrial (LaCOMMARE e ETO, 2006). Os investimentos realizados para adequação dos sistems de subtransmissão e distribuição são capazes de melhorar esses indicadores no médio e longo prazo.

Os indicadores foram escolhidos tomando-se por base a aderência de cada um deles às proposições do estudo 
(determinadas na Introdução), bem como sua utilização e percepção pelo mercado. Não faria sentido escolher indicadores, tanto financeiros quanto técnicos, muito conhecidos e utilizados pelo meio acadêmico e empresarial, mas com pouca aderência às proposições da pesquisa. Nem tão pouco, muita aderência às proposições da pesquisa e pouca aplicabilidade no mercado.

Nesse sentido, quatro indicadores distintos foram utilizados neste estudo: dois financeiros e dois técnicos. Os indicadores financeiros utilizados são o EBITDA e o Resultado do Exercício. Os indicadores técnicos utilizados são o DEC e o FEC.

\section{INDICADORES FINANCEIROS: EBITDA E RESULTADO DO EXERCÍCIO}

EBITDA é uma medida de avaliação de desempenho que parte do lucro e ajusta alguns valores do resultado, estimando o fluxo de caixa gerado pelas atividades operacionais. Assim, descontam-se do lucro os valores que não afetam o caixa, como depreciações e amortizações. Descontam-se ainda despesas financeiras de empréstimos e financiamentos (juros), incluindo descontos aos clientes, juros pagos a fornecedores e outros.

O EBITDA consiste num poderoso indicador de desempenho financeiro, posto que reflete o potencial de geração de recursos decorrentes das atividades operacionais da empresa. Dessa forma, esse indicador mensura o potencial operacional de caixa que o ativo operacional de uma empresa é capaz de gerar, não sendo levado em consideração o custo de eventual capital tomado emprestado nem computadas as despesas e receitas financeiras, os eventos extraordinários e os ganhos ou perdas não operacionais, as despesas com depreciação, amortização, exaustão e impostos que incidem sobre o lucro (Imposto de Renda e Contribuição Social sobre o Lucro Líquido).

Vasconcelos (2002; 2001a) salienta que o EBITDA, misto de indicador de desempenho econômico-financeiro e base para avaliação de empresas, tem se mostrado bastante eficaz nas análises empresariais, o que ressalta sua importância. Para a autora, a discussão de indicadores de desempenho é um tema cuja relevância, no que tange à avaliação de empresas, adere ao contexto moderno e especialmente organizacional, cenário de inúmeras reestruturações societárias dos últimos anos, de onde emerge a necessidade de se saber o real valor de um negócio.

Da mesma forma, outros autores destacam a importância do EBITDA como indicador de desempenho financeiro e também como indicador auxiliar para valoração de empresas e apoio no processo de tomada de decisão de gerentes, parceiros em potencial, investidores e analistas (MARTINS, 1998; ASSAF NETO, 2002; SANTANA e LIMA, 2004).

A utilização desse indicador é vantajosa na medida em que informa o desempenho da empresa na atividade, assim como o grau de cobertura das despesas financeiras, e nos permite responder aos seguintes questionamentos: Os resultados operacionais cobrem as despesas financeiras? Qual a margem de segurança necessária para pagar essas despesas? Permite também monitorar as estratégias financeiras empreendidas e funciona como instrumento de avaliação da empresa, uma vez que evidencia a viabilidade dos negócios em seu segmento.

No entanto, existem algumas limitações para utilização do indicador. Superdimensionar as funções informativas do indicador é reduzir sua eficácia e introduzir o risco de interpretação dos resultados. Como ressalva, vale lembrar que o EBITDA pode dar uma falsa ideia sobre a efetiva liquidez da empresa. Além disso, o indicador não considera o montante de reinvestimento requerido (pela depreciação), fator especialmente crítico nas empresas que apresentam ativos operacionais de vida curta. O indicador também não leva em conta o capital investido no negócio, o que pode ser classificado como uma limitação. Ampla discussão sobre as vantagens e desvantagens do indicador EBITDA pode ser aprofundada em Santana e Lima (2004), Vasconcelos (2002; 2001b), Icó e Braga (2001), Assaf Neto (2002), Hamilton (2003) e Mendez (2007).

Mesmo apresentando algumas desvantagens, o EBITDA é um indicador financeiro muito relevante e popular, mas que deve ser utilizado combinado com outros indicadores de desempenho para fornecer uma visão mais apropriada do desempenho da empresa. Ainda assim, é certamente um dos mais acompanhados pelos analistas e acaba ganhando bastante importância também na análise de crédito (geralmente realizadas por bancos e instituições financeiras) e em avaliação de empresas. Outros estudos também apresentam sucesso ao utilizar o EBITDA como indicador de desempenho financeiro, tais como Trejo-Pech e outros (2006), Kalay e outros (2007), King e Segal (2008), entre outros.

O Resultado do Exercício considera, além do resultado operacional (expresso pelo EBITDA), o resultado financeiro, os impostos e a depreciação, sendo portanto um indicador mais econômico, mas ainda assim muito popular nos círculos de negócios. Expressa, além da fotografia operacional da distribuidora, o panorama total, incluindo esses fatores que também impactam seu resultado final para o exercício, e por essas razões será também muito importante nessa análise. 


\section{INDICADORES TÉCNICOS: DEC E FEC}

Em virtude de ser uma atividade econômica altamente regulada, de utilidade pública e, pela natureza da mesma, com características de monopólio, é de suma importância a verificação periódica da qualidade do serviço de fornecimento de energia elétrica prestado aos consumidores pelas concessionárias. Tal verificação empírica torna-se possível utilizando-se os índices de medição da qualidade do serviço prestado, quais sejam: Duração Equivalente de Interrupção por Unidade Consumidora (DEC) e Frequência Equivalente de Interrupção por Unidade Consumidora (FEC). O DEC e o FEC são amplamente utilizados no setor e comumente usados como padrão nos EUA, Canadá e países da Europa.

$\mathrm{Na}$ realidade, a qualidade do serviço prestado sempre foi de extrema importância para sistemas elétricos e é possível encontrar inúmeros trabalhos que descrevem diferentes aspectos do tópico em questão, tais como Billinton e Billinton (1989), Goel e Billinton (1991), Warren e outros (2003), Chowdhury e outros (2003), Billinton e outros (2004), Chowdhury e Koval (2004), Willians e Robinson (2005), entre outros.

No Brasil, a partir de 1995, no período pós-Plano Real, houve uma intensificação do consumo de energia elétrica (BNDES, 2000). A oferta de energia elétrica, no entanto, não aumentou na mesma proporção, fazendo com que a tendência natural esperada fosse a piora dos indicadores de qualidade de fornecimento das distribuiAssim, de acordo com Resolução da ANEEL n ${ }^{\circ}$ 24, de 27 de janeiro de 2000 , em seu artigo $4^{\circ}$, "a partir de janeiro de 2000 , os indicadores de continuidade deverão ser apurados por meio de procedimentos auditáveis e que contemplem desde o nível de coleta de dados das interrupções até a transformação desses dados em indicadores". Nesse sentido, a partir da resolução de 2000, esses indicadores são controlados pela ANEEL, que monitora e determina metas para sua melhoria para cada uma das distribuidoras de energia elétrica do país. A melhoria desses índices está relacionada aos montantes de recursos investidos na ampliação e melhoria dos sistemas de subtransmissão das distribuidoras (redes e subestações).

No Brasil, os indicadores DEC e FEC têm suas definições estabelecidas na Portaria do Departamento Nacional de Águas e Energia Elétrica - DNAEE ${ }^{\circ}$ 46, de 17 de abril de 1978, e retificadas pela Resolução ANEEL n 12, de 27 de janeiro de 2000, conforme a seguir:

O DEC expressa o período de tempo que, em média, cada unidade consumidora ficou privada de fornecimento de energia elétrica, no período considerado, geralmente um ano. É calculado da seguinte forma: DEC $=$ Tempo total das interrupções observadas em um ano / Número total de consumidores, e é medido em minutos ou horas. O FEC expressa o número de interrupções que, em média, cada unidade consumidora sofreu, no período considerado, geralmente um ano. É calculado da seguinte forma: FEC $=$ Número total de interrupções observadas em um ano / Número total de consumidores.

Os indicadores técnicos (DEC e FEC), portanto, dão um bom panorama da qualidade do serviço prestado pelas distribuidoras de energia elétrica aos seus consumidores. Quanto menor forem esses indicadores, melhor é a qualidade do serviço prestado pelas companhias e vice-versa.

\section{METODOLOGIA}

Para elaboração deste estudo, cinco distribuidoras de energia elétrica foram analisadas: CEAL, CEPISA, CELPE, CEMAR e SAELPA. A escolha das empresas que fazem parte do estudo foi feita com base em sua natureza (privadas ou públicas), ano de privatização (para as privatizadas) e contexto do mercado (pertencentes ao SIN - Sistema Interligado Nacional). Segundo dados da Associação Brasileira de Distribuidores de Energia Elétrica (ABRADEE), a CELPE foi privatizada em 20 de fevereiro 2000, a CEMAR em 15 de junho 2000 e a SAELPA em 31 de novembro 2000. Apesar das datas distintas, optouse por empresas que foram privatizadas no mesmo ano (2000), descartando-se os indicadores para o referido ano. A adoção dessa estratégia mostra-se importante, pois o ano de privatização consiste no marco de análise deste estudo e isolam-se assim possíveis distorções em seus resultados finais. Com base nos dados anualizados e agregados (antes e depois da privatização) e escolhendo empresas privatizadas em um mesmo ano, foi possível uniformizar os dados sob outros aspectos, tais como: ciclos econômicos, inflação, recessão, racionamento, ciclos hidrológicos, entre outros. Caso essa estratégia não fosse aplicada, haveria um descasamento entre os dados obtidos das diferentes empresas, o que poderia gerar dificuldades em sua análise e trazer distorções aos resultados finais do estudo.

Optou-se por um período de análise de 12 anos, entre 1997 e 2008, para todas as cinco empresas e todos os quatro indicadores que fazem parte deste estudo. Tomando o ano de 2000 como o ano base, a análise se deu três anos antes (1997, 1998 e 1999) e oito anos depois do ano base determinado (de 2001 a 2008).

Além disso, priorizaram-se as distribuidoras localizadas em uma mesma região do país (Nordeste do Brasil), em 
virtude das similaridades de mercados, políticas públicas e impostos, incentivos, preços de suprimento e fornecimento e aspectos culturais. Especificamente em relação às empresas federais de distribuição, optou-se por aquelas que estão conectadas ao SIN. As demais empresas federais de distribuição estão localizadas em áreas isoladas, que possuem regulação própria e diferente das aplicadas ao SIN (Amazonas, Acre e Rondônia, por exemplo).

Para análise dos indicadores considerados, as informações necessárias foram coletadas junto aos balanços das empresas, relatórios de administração, informações disponíveis para o mercado, publicações setoriais, relatórios, apresentações e sites de associações setoriais, contatos diretos com as empresas e visitas às suas instalações e outros documentos técnicos, assim como as informações da base de dados SÉRIES (1999, 2000, 2001, 2004 e 2005). As informações obtidas foram verificadas junto às empresas e junto ao banco de dados da ABRADEE.

As informações coletadas foram trabalhadas para apoiar a análise das proposições estabelecidas anteriormente. A observação do EBTIDA e do Resultado do Exercício constituem o suporte para a análise da Proposição 1. Os indicadores técnicos formam a base para a análise da Proposição 2. O tratamento dos dados e informações obtidas é especificado na seção que trata dos resultados da pesquisa de campo.

As informações relacionadas ao EBITDA e ao Resultado do Exercício das concessionárias foram trabalhadas para aumentar as chances de visualização de conclusões em relação às mesmas. A unidade de medida utilizada neste trabalho para os indicadores financeiros foi milhões de Reais (R\$ milhões) - Tabelas 1, 2, 3 e 4. As informações relacionadas ao DEC das concessionárias foram trabalhadas em termos absolutos (em horas) - Tabelas 5 e 6. O tratamento de dados utilizado para o indicador DEC foi também aplicado para o indicador FEC (número de interrupções) - Tabelas 7 e 8.

\section{AS EMPRESAS DE DISTRIBUIÇÃO DE ENERGIA ELÉTRICA ANALISADAS}

As cinco distribuidoras de energia elétrica estudadas são responsáveis, em conjunto, por mais de 6,7 milhões de consumidores, atendendo uma população total de cerca de 24,6 milhões. Essa população total atendida por essas empresas é comparável, por exemplo, com as populações de quatro países europeus somadas: Suécia, Noruega, Finlândia e Dinamarca. A área coberta pelas cinco distribuidoras é de aproximadamente 766.658 quilômetros qua- drados, maior que a área total de países como França ou Espanha, por exemplo (Figura 1). No entanto, os estados estudados contemplam as regiões mais pobres do país com base em seus Produtos Internos Brutos (PIB) per capita.

As empresas federais de distribuição de energia elétrica são aquelas que não foram vendidas no Governo Fernando Henrique Cardoso sob as diretrizes do PND. Essas distribuidoras são geridas e financiadas pela ELETROBRÁS, o que Carregaro (2003) classifica como dificuldade, devido à diversidade de ações da holding no setor (dentro dos segmentos de geração, transmissão, distribuição, comercialização, administração de fundos federais, pesquisa e desenvolvimento e agente promotor, integrador e coordenador de investimentos no setor), à grande área abrangida pelas suas operações e à heterogeneidade das empresas sob seu controle. Duas empresas federais de distribuição, conectadas ao SIN, estão atualmente sob o controle e financiamento da ELETROBRÁS: a CEAL e a CEPISA.

A Companhia Energética de Alagoas, CEAL (http:// www.ceal.com.br/), criada em 1959, como Companhia de Eletricidade de Alagoas, foi federalizada em 1997, comprada pela ELETROBRÁS ao Governo do Estado de Alagoas. A companhia tem o direito de concessão exclusivo para distribuição de energia elétrica em todo o Estado de Alagoas, cobrindo uma área de 27.768 quilômetros quadrados e atendendo uma população total de cerca de 3,0 milhões de habitantes (Figura 1). Com base no ano de 2006, o PIB per capita do Estado de Alagoas é de R $\$ 5.164$ ( $25^{\circ}$ dentre os 27 estados da Federação), bem abaixo do PIB per capita do país, que é de R $\$ 12.688$ (IBGE, 2007). Do total das ações da CEAL, 75,17\% pertencem à ELETROBRÁS, $18,20 \%$ ao BNDESPAR (BNDES Participações), 3,36\% aos municípios e $3,27 \%$ a outros acionistas. A CEAL possui um total de 2.223 empregados e 804.964 consumidores (Relatório de Administração 2008).

A Companhia Energética de Piauí, CEPISA (http:// www.cepisa.com.br/), foi criada em 1962 e federalizada em 1997, comprada pela ELETROBRÁS ao Governo do Estado do Piauí. A empresa possui o direito de concessão exclusivo para distribuição de energia elétrica no Estado do Piauí, cobrindo uma área de 251.529 quilômetros quadrados e atendendo uma população total de aproximadamente 3,0 milhões de pessoas. Com base no ano de 2006, o PIB per capita do Estado do Piauí é de R $\$ 4.213$ - $27^{\circ}$ dentre os 27 estados da Federação (IBGE, 2007). Do total das ações da CEPISA, 98,56\% pertencem à ELETROBRÁS, 0,5\% aos municípios e $0,94 \%$ a outros acionistas. A CEPISA possui um total de 3.030 empregados e 848.762 consumidores (Relatório de Administração 2008). 
A Companhia Energética de Pernambuco, CELPE (http://www.celpe.com.br/), criada em 1965, foi privatizada em 2000. A empresa possui o direito de concessão exclusivo no Estado de Pernambuco, cobrindo uma área de 98.938 quilômetros quadrados e atendendo uma população de 8,7 milhões de pessoas. As ações da CELPE pertencem $89,65 \%$ à Neoenergia (grupo de investidores privado), $1,56 \%$ à ELETROBRÁS e $8,79 \%$ a outros acionistas. Com base no ano de 2006, o PIB per capita do Estado de Pernambuco é de R $\$ 6.528-21^{\circ}$ dentre os 27 estados da Federação (IBGE, 2007). A CELPE tem um número total de empregados de 7.024 e um total de 2.859.645 consumidores (Relatório de Administração 2008).

A Companhia Energética do Maranhão, CEMAR (http://www.cemar-ma.com.br/), criada em 1958 como Centrais Elétricas do Maranhão, foi também privatizada em 2000 e consiste na distribuidora de energia elétrica exclusiva para todo o Estado do Maranhão, cobrindo uma área de 331.983 quilômetros quadrados e atendendo uma população de aproximadamente 6,1 milhões de habitantes. Com base no ano de 2006, o PIB per capita do Estado do Maranhão é de R $\$ 4.628$ - $26^{\circ}$ dentre os 27 estados da Federação (IBGE, 2007). As ações da CEMAR pertencem $64,81 \%$ à Equatorial Energia (grupo de investidores privado), 33,62\% à ELETROBRÁS e 1,57\% a outros acionistas. A CEMAR possui um número total de 5.591 empregados e um total de 1.535 .235 consumidores (Relatório de Administração 2008).

A Sociedade Anônima de Eletrificação da Paraíba, SAELPA (http://www.saelpa.com.br/), criada em 1964, está em processo de troca de nome para Energisa Paraíba. A empresa foi privatizada em 2000 e possui o direito de concessão para distribuição de energia elétrica no Estado da Paraíba, cobrindo uma área de 56.440 quilômetros quadrados e atendendo uma população total de cerca de 3,8 milhões de pessoas. Com base no ano de 2006, o PIB per capita do Estado da Paraíba é de R\$5.507 - $24^{\circ}$ dentre os 27 estados da Federação (IBGE, 2007). As ações da SAELPA pertencem $82,83 \%$ à Energisa CataguazesLeopoldina (grupo de investidores privados), 13,12\% à ELETROBRÁS e 4,05\% a outros acionistas. A SAELPA possui um total de 2.219 empregados e 1.016.077 consumidores (Relatório de Administração 2008).

Figura 1 - Região nordeste do Brasil e distribuidoras analisadas.

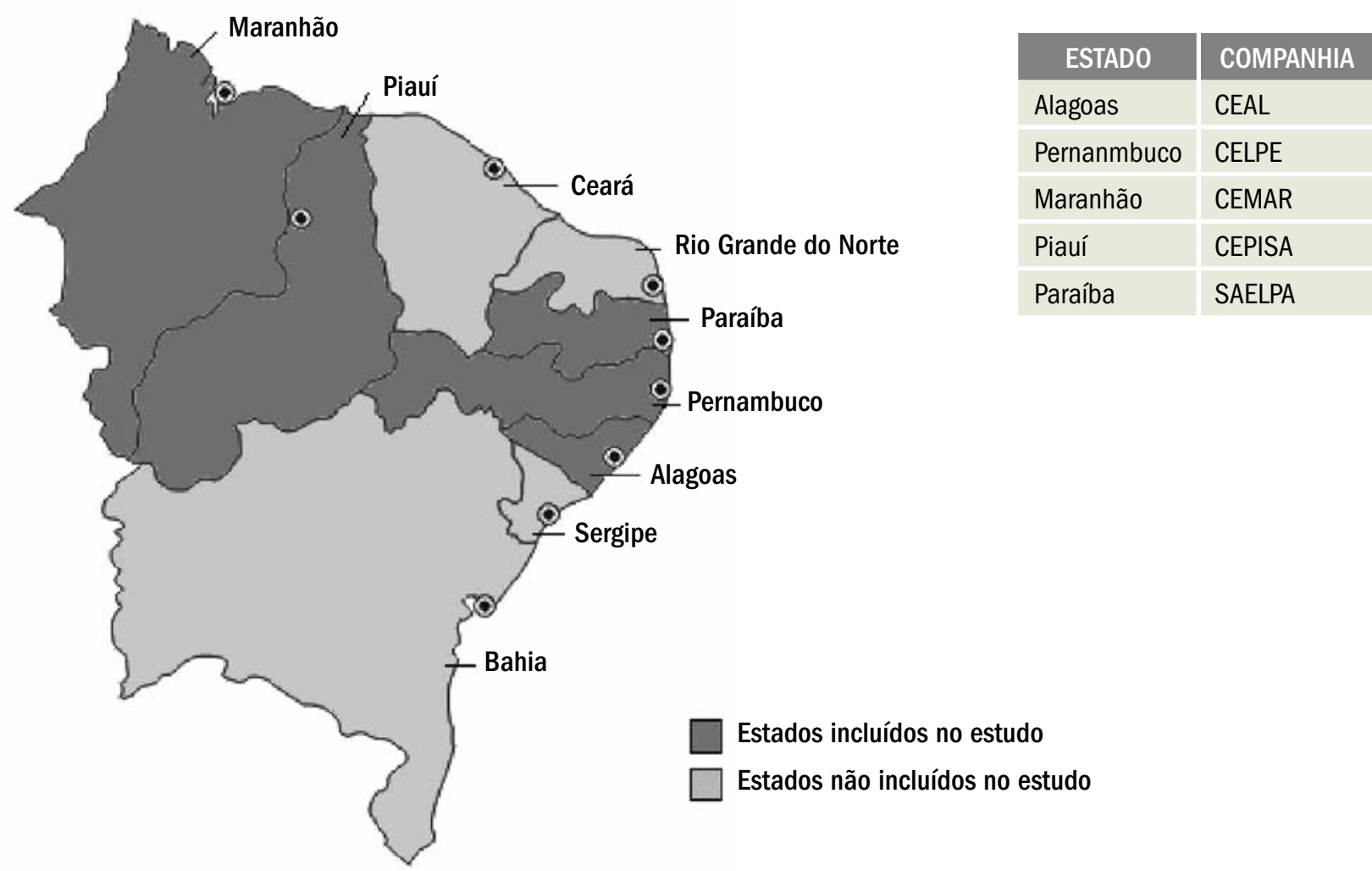




\section{RESULTADOS DA PESQUISA}

Em relação ao EBITDA, as empresas apresentam panoramas distintos e alguns até curiosos (Tabela 1 e Gráfico 1). A CELPE é uma empresa que apresenta uma evolução bastante positiva nesse indicador que representa a geração de recursos por meio das atividades operacionais da empresa. Há um salto desse indicador de cerca de R \$ 57,0 milhões, em 1997, para mais de $\mathrm{R} \$ 691,7$ milhões, em 2008. O EBITDA acumulado nos 12 anos de estudo apresenta um montante de mais de $\mathrm{R} \$ 3.482,8$ milhões, perfazendo uma média anual bastante significativa de cerca de $\mathrm{R} \$ 290,2$ milhões nesse período.

A CEMAR e a SAELPA também apresentam tendência de crescimento. Passam de cerca de $\mathrm{R} \$ 37,0$ milhões e $\mathrm{R} \$ 13,1$ milhões, em 1997, para mais de $\mathrm{R} \$ 415,5 \mathrm{mi}-$ lhões e R\$ 173,8 milhões, respectivamente, em 2008. O curioso é que em ambas empresas o EBITDA apre- senta queda brusca exatamente no ano da privatização, 2000, com a retomada da tendência de crescimento a partir de 2001. O ano de 2001 foi o ano da crise energética brasileira (racionamento). Essa queda brusca no ano de 2000 impacta o EBITDA acumulado e a média anual do EBITDA no período para as duas concessionárias (Tabela 1).

A CEAL e a CEPISA, as duas empresas federais de distribuição, apresentam alguma melhora no indicador nos últimos anos do estudo, com grandes oscilações no decorrer do período. O EBITDA acumulado no período da CEAL é de cerca de R \$ 507,1 milhões, com uma média anual de R \$2,3 milhões. Já a CEPISA apresenta o indicador acumulado menor que zero (negativo), em $\mathrm{R} \$ 4,5$ milhões, mas vem mostrando recuperação nos últimos anos. Essa situação mostra que a companhia não foi capaz de gerar recursos financeiros por meio de suas atividades operacionais no período.

Tabela 1 - Evolução do EBITDA das concessionárias, por ano

\begin{tabular}{|l|r|r|r|r|r|r|r|r|r|r|r|r|r|r|}
\hline & 1997 & 1998 & 1999 & 2000 & 2001 & 2002 & 2003 & 2004 & 2005 & 2006 & 2007 & 2008 & TOTAL & MÉDIA \\
\hline CEAL & 22.8 & 32.4 & 28.0 & 45.1 & $(22.0)$ & 23.3 & 16.1 & 51.5 & 84.8 & 42.3 & 49.4 & 133.4 & 507.1 & 42.3 \\
\hline CEPISA & 3.2 & 8.3 & $(3.3)$ & 11.7 & 10.4 & $(41.6)$ & $(38.1)$ & $(23.4)$ & $(26.0)$ & 4.4 & 22.8 & 67.1 & $(4.5)$ & $(0.4)$ \\
\hline CELPE & 57.0 & 88.0 & 141.7 & 169.1 & 256.8 & 160.3 & 250.1 & 265.3 & 388.4 & 430.3 & 584.1 & 691.7 & $3,482.8$ & 290.2 \\
\hline CEMAR & 37.0 & 76.4 & 40.3 & $(72.8)$ & 17.6 & 90.8 & 93.2 & 85.4 & 188.6 & 344.0 & 388.0 & 415.5 & $1,703.9$ & 142.0 \\
\hline SAELPA & 13.1 & 12.5 & 14.5 & $(99.8)$ & 7.8 & 90.6 & 85.7 & 109.9 & 155.1 & 162.2 & 200.6 & 173.8 & 926.0 & 77.2 \\
\hline
\end{tabular}

Gráfico 1 - Evolução do EBITDA das concessionárias, por ano

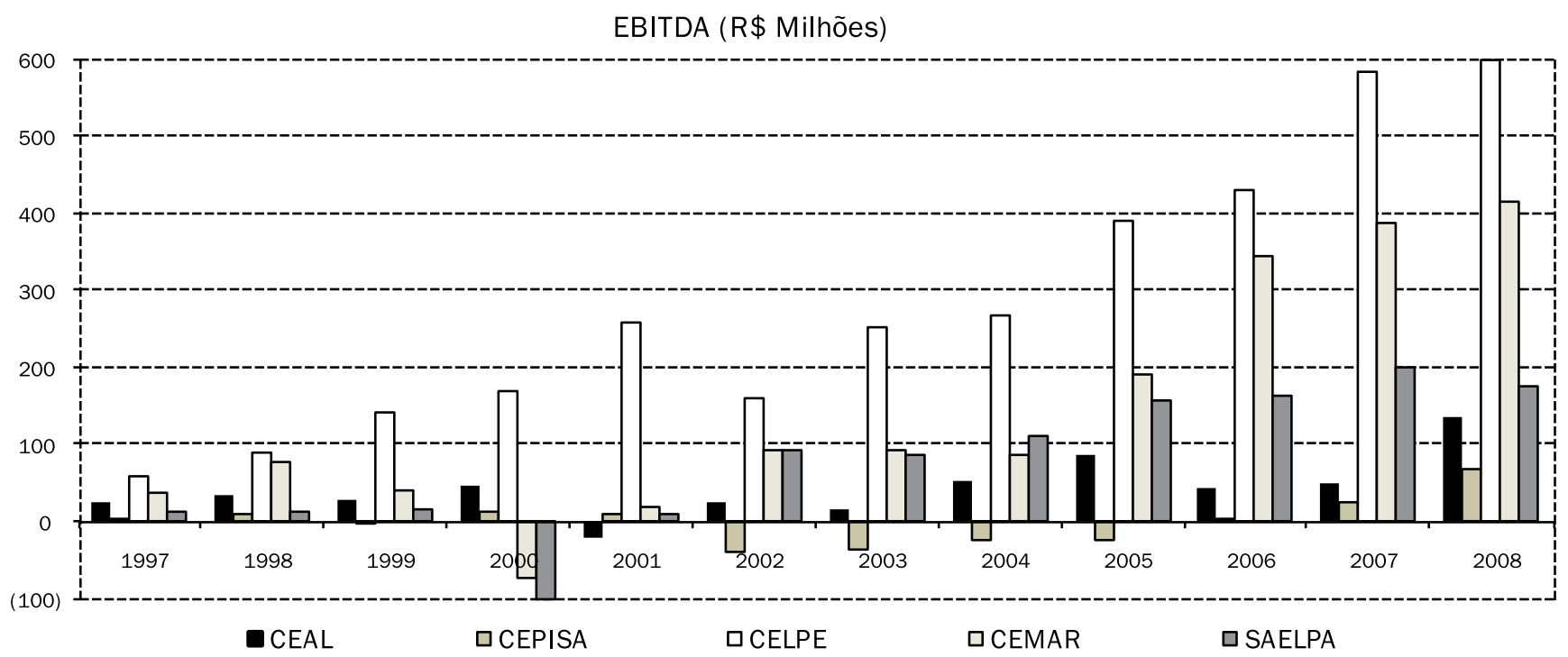


A Tabela 2 mostra a evolução do indicador antes e depois do ano da privatização das concessionárias que passaram por esse processo (ano de 2000). Pode-se perceber que as distribuidoras que foram privatizadas apresentaram aumento de no mínimo 296\% (casos da CELPE e da CEMAR) no seus EBITDA após a privatização. A SAELPA foi a que mostrou uma evolução mais surpreendente, aumentando seu EBITDA médio em $821 \%$ depois da privatização.

Já as distribuidoras que continuaram sob o controle do Estado mostraram uma evolução muito aquém daquelas distribuidoras que foram privatizadas. A CEAL mostrou um aumento da média de seu EBITDA de $71 \%$, enquanto a CEPISA teve a média diminuída em $212 \%$ (negativo) no período após o ano 2000.

Em relação ao Resultado do Exercício, as empresas apresentam panoramas distintos (Tabela 3). A CELPE é uma empresa que apresenta uma evolução bastante positiva nesse indicador, mostrando prejuízo apenas no ano de sua venda. Ela sai de um resultado de $\mathrm{R} \$ 56,6 \mathrm{mi}-$ lhões, em 1997, para R\$466,3 milhões, em 2008, com lucros acumulados de R \$ 1.585,3 milhões. A evolução da SAELPA também pode ser observada como agressiva no período, com prejuízos apenas na época da crise e lucros acumulados de cerca de R $\$ 352,1$ milhões nos 12 anos do estudo. A CEMAR apresentou um período de dificul- dades mais extenso (de 1999 a 2004), mas recuperou-se e apresenta um lucro acumulado no período de cerca de $\mathrm{R} \$ 320,1$ milhões.

As empresas federais de distribuição, CEAL e CEPISA, mostram evolução na contramão da tendência das demais distribuidoras privatizadas. Essas distribuidoras apresentam prejuízos na quase totalidade dos exercícios considerados (exceto 1999 para a CEPISA e exceto 1999, 2000, 2005 e 2008 para a CEAL). Nos 12 anos do estudo, a CEAL apresenta um prejuízo acumulado de $\mathrm{R} \$ 333,0$ milhões, enquanto a CEPISA apresenta um prejuízo acumulado de R\$ 910,4 milhões.

A Tabela 4 mostra a evolução do indicador antes e depois do ano da privatização das concessionárias que passaram por esse processo (ano de 2000). Pode-se perceber que todas as distribuidoras que foram privatizadas apresentaram aumento mínimo de 199\% (caso da CELPE) nos seus resultados médios após a privatização. A CEMAR foi a que mostrou uma evolução mais surpreendente, aumentando seu resultado médio em $526 \%$ no período após a privatização.

As distribuidoras que continuaram sob o controle do Estado (CEAL e CEPISA) mostraram uma evolução muito aquém daquelas distribuidoras que foram privatizadas. A CEAL mostrou uma diminuição da média de seu resultado de $127 \%$ (negativo), enquanto a CEPISA teve a média

Tabela 2 - Média do EBITDA das concessionárias, antes e depois de 2000, e variação

\begin{tabular}{|l|r|r|c|}
\hline \multicolumn{7}{|c|}{ EBITDA MÉDIO ANTES E DEPOIS DE 2000 (R\$ MILHÕES) } \\
\hline & ANTES & DEPOIS & VAR \\
\hline CEAL & 27.7 & 47.3 & $71 \%$ \\
\hline CEPISA & 2.7 & $(3.1)$ & $-212 \%$ \\
\hline CELPE & 95.6 & 378.4 & $296 \%$ \\
\hline CEMAR & 51.2 & 202.9 & $296 \%$ \\
\hline SAELPA & 13.4 & 123.2 & $821 \%$ \\
\hline
\end{tabular}

Tabela 3 - Evolução do resultado do exercício das concessionárias, por ano

\begin{tabular}{|c|c|c|c|c|c|c|c|c|c|c|c|c|c|c|}
\hline \multicolumn{15}{|c|}{ RESULTADO DO EXERCÍCIO (R\$ MILHÕES) } \\
\hline & 1997 & 1998 & 1999 & 2000 & 2001 & 2002 & 2003 & 2004 & 2005 & 2006 & 2007 & 2008 & TOTAL & MÉDIA \\
\hline CEAL & (31.3) & $(38.0)$ & 22.0 & 1.1 & (54.9) & (64.9) & $(46.9)$ & $(13.4)$ & 12.5 & $(136.1)$ & $(22.7)$ & 39.5 & $(333.0)$ & $(27.8)$ \\
\hline CEPISA & (41.6) & (31.9) & 1.6 & (60.9) & (63.4) & $(216.8)$ & (95.6) & $(52.2)$ & (100.4) & (69.1) & $(81.2)$ & (98.7) & (910.4) & (75.9) \\
\hline CELPE & 56.6 & 58.4 & 67.1 & (50.4) & 135.6 & 12.9 & 97.9 & 76.7 & 134.8 & 217.8 & 311.5 & 466.3 & $1,585.3$ & 132.1 \\
\hline CEMAR & 20.5 & 5.4 & $(72.2)$ & $(159.7)$ & $(214.1)$ & $(120.8)$ & $(53.0)$ & (31.1) & 359.7 & 177.5 & 180.1 & 227.8 & 320.1 & 26.7 \\
\hline SAELPA & 1.0 & 37.8 & 4.4 & (93.8) & (13.3) & 27.4 & 36.0 & 20.9 & 72.1 & 70.2 & 87.9 & 101.6 & 352.1 & 29.3 \\
\hline
\end{tabular}


diminuída em mais de 305\% (negativo) no período após o ano 2000.

O DEC é um indicador que mede a duração da interrupção do fornecimento de energia elétrica que os consumidores sofreram, em média, no exercício (período de um ano), medido em horas. Assim, quanto menor for o indicador observado, melhor é. As concessionárias de distribuição investem recursos financeiros para melhorar esse indicador, ou seja, diminuí-lo. Para se ter uma base de comparação, o DEC médio brasileiro (para todas as distribuidoras do país) evoluiu de 27,2 horas em 1997 para 16,1 horas em 2007.

Conforme pode ser observado na Tabela 5, CEMAR, SAELPA e CEPISA apresentam uma média do DEC no pe- ríodo estudado superior a 40 horas de interrupções médias por ano, por unidade consumidora. A CEAL apresenta média no período de 28,5 horas. A CELPE é a distribuidora que apresenta a melhor média no período estudado, em termos absolutos, ou seja, cerca de 15,4 horas de interrupções por ano, por unidade consumidora.

De forma geral, todas as concessionárias apresentaram uma tendência de melhora no DEC nos últimos anos do período estudado, com pequenas oscilações para cima ou para baixo (Tabela 5 e Gráfico 2).

A SAELPA apresenta uma trajetória interessante: apesar do DEC significativo em 1997 e do pico em 1998 (55,1 e 94,7 respectivamente), a partir de 1999 até 2001 acontece uma rápida e surpreendente recuperação desse indicador.

Tabela 4 - Média do Resultado do exercício das concessionárias, antes e depois de 2000, e variação

\begin{tabular}{|l|c|c|c|}
\hline \multicolumn{5}{|c|}{ RESULTADO DO EXERCÍCIO MÉDIO ANTES E DEPOIS DE 2000 (R\$ MILHÕES) } \\
\hline & ANTES & DEPOIS & VAR \\
\hline CEAL & $(15.8)$ & $(35.9)$ & $-127 \%$ \\
\hline CEPISA & $(24.0)$ & $(97.2)$ & $-305 \%$ \\
\hline CELPE & 60.7 & 181.7 & $199 \%$ \\
\hline CEMAR & $(15.4)$ & 65.8 & $526 \%$ \\
\hline SAELPA & 14.4 & 50.3 & $250 \%$ \\
\hline
\end{tabular}

Tabela 5 - Evolução do DEC das concessionárias, por ano

\begin{tabular}{|l|l|l|l|l|l|}
\hline \multirow{2}{*}{ ANO } & \multicolumn{3}{|c|}{ DEC (HORAS) } & \\
\hline 1997 & CEAL & CEPISA & CELPE & CEMAR & SAELPA \\
\hline 1998 & 44.5 & 74.7 & 18.4 & 44.0 & 55.1 \\
\hline 1999 & 34.7 & 67.1 & 14.3 & 49.3 & 40.7 \\
\hline 2000 & 30.9 & 57.7 & 15.5 & 36.9 & 34.2 \\
\hline 2001 & 35.1 & 56.4 & 16.3 & 38.7 & 21.1 \\
\hline 2002 & 27.7 & 43.0 & 15.5 & 67.5 & 22.7 \\
\hline 2003 & 29.9 & 45.3 & 16.2 & 66.8 & 25.4 \\
\hline 2004 & 28.2 & 50.7 & 12.9 & 67.9 & 38.1 \\
\hline 2005 & 23.6 & 50.9 & 16.0 & 63.4 & 46.3 \\
\hline 2006 & 21.0 & 52.2 & 13.0 & 54.6 & 50.8 \\
\hline 2007 & 19.6 & 51.7 & 15.8 & 42.4 & 36.1 \\
\hline MÉDIA & 28.5 & 45.0 & 15.1 & 28.7 & 34.5 \\
\hline TOTAL & 342.5 & 51.5 & 15.5 & 27.3 & 41.6 \\
\hline
\end{tabular}


De 2002 em diante, a distribuidora perde o controle do indicador, retomando a trajetória de baixa em 2007.

A CEAL vem apresentando uma trajetória de recuperação do indicador e o mantendo em níveis baixos, assim como a CELPE, que é a melhor das distribuidoras analisadas, mantendo o indicador em torno de 15 horas. A CEMAR, a partir de 2000, perdeu o controle do indicador, mas mostra recuperação nos cinco últimos anos. A CEPISA também vem se esforçando para reduzir o DEC, mas não têm obtido sucesso, mantendo-se em patamares bastante elevados, sendo a pior de todas as cinco distribuidoras estudadas nesse indicador, em termos absolutos.

Comparando a evolução do DEC médio das distribuidoras nos períodos anterior e posterior ao ano da priva- tização (e excluindo da análise o ano de 2000), podemos observar por meio da Tabela 6 que a CEPISA conseguiu reduzir o indicador no período após 2000 em cerca de $27 \%$, a CEAL em cerca de $33 \%$ e a SAELPA em cerca de $46 \%$. Apesar de ser a distribuidora com melhor DEC em termos absolutos, a CELPE apresentou redução de apenas $7 \%$ depois da privatização. A CEMAR foi a única distribuidora que apresentou piora no indicador no período após 2000 , de aproximadamente $21 \%$, na contramão da tendência apresentada pelas demais distribuidoras.

O FEC é um indicador que mede o número de vezes que os consumidores tiveram o fornecimento de energia elétrica interrompido, em média, no exercício (durante um ano). Igualmente ao DEC, quanto menor for o indicador

\section{Gráfico 2 - Evolução do DEC por concessionária, por ano}

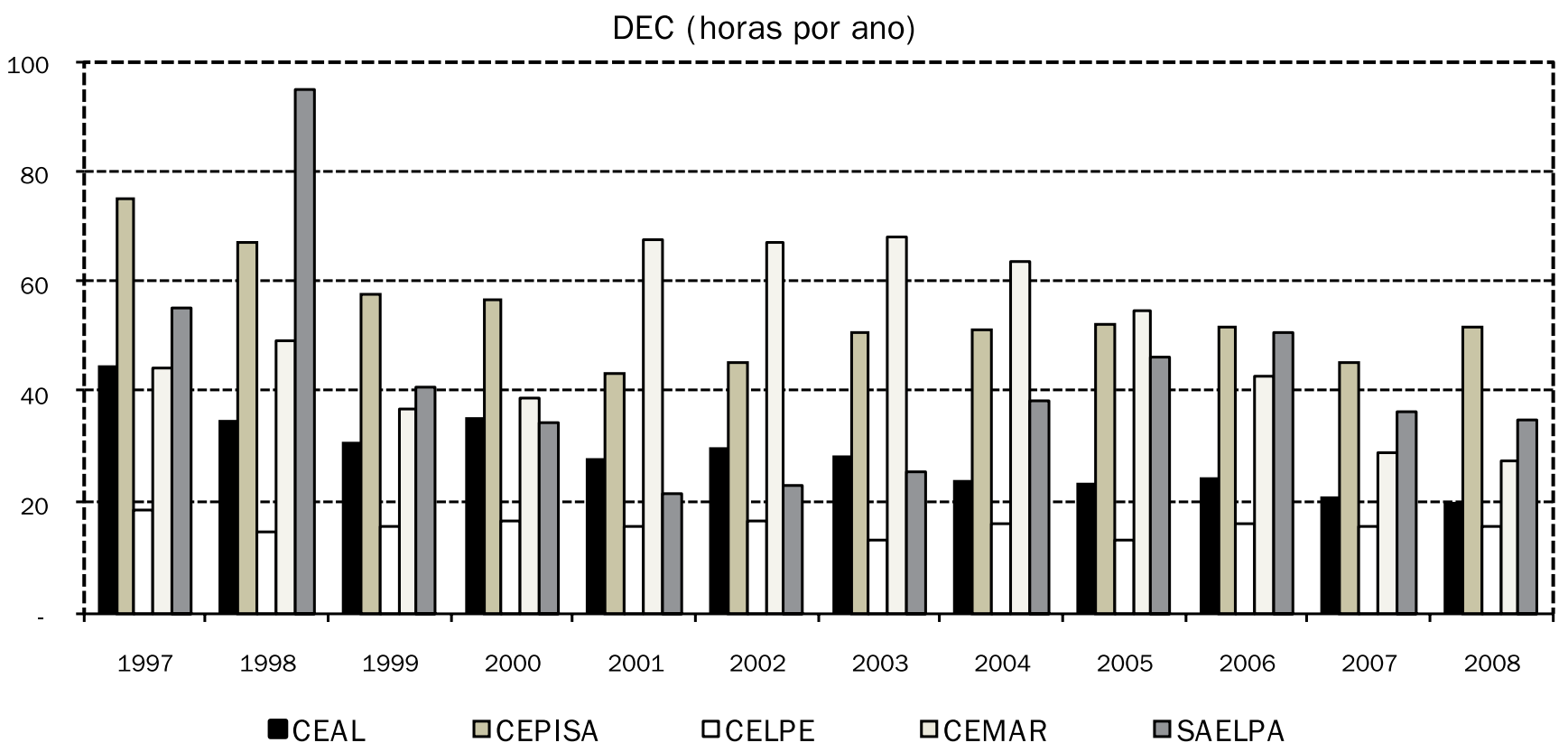

Tabela 6 - Média do DEC das concessionárias, antes e depois de 2000, e variação

\begin{tabular}{|l|c|c|c|}
\hline \multicolumn{4}{|c|}{ MÉDIA DO DEC ANTES E DEPOIS DE 2000 } \\
\hline & ANTES & DEPOIS & VAR \\
\hline CEAL & 36.7 & 24.7 & $-33 \%$ \\
\hline CEPISA & 66.5 & 48.8 & $-27 \%$ \\
\hline CELPE & 16.1 & 15.0 & $-7 \%$ \\
\hline CEMAR & 43.4 & 52.3 & $21 \%$ \\
\hline SAELPA & 63.5 & 34.4 & $-46 \%$ \\
\hline
\end{tabular}


observado, melhor é. As concessionárias de distribuição também investem recursos financeiros para melhorar esse indicador, ou seja, diminuí-lo. Para se ter uma base de comparação, o FEC médio brasileiro (para todas as distribuidoras do país) evoluiu de 21,7 interrupções em 1997 para 11,7 interrupções em 2007.

Conforme pode ser observado na Tabela 7 , a CEMAR e a CEPISA apresentam uma média do FEC no período estudado em torno de 30 interrupções médias por ano ou mais, por unidade consumidora. A SAELPA apresenta média no período de 23,8 interrupções e a CEAL apresenta média no período de 20,9 interrupções. A CELPE é a distribuidora que apresenta a melhor média, em termos absolutos, no período estudado: 11,8 interrupções.

De forma geral, todas as concessionárias apresentaram uma tendência de melhora no FEC nos últimos anos do período estudado, com pequenas oscilações para cima ou para baixo (Tabela 7 e Gráfico 3). A SAELPA apresenta uma trajetória interessante: apesar do FEC significativo em 1997 e do pico em 1998 (34,8 e 59,2, respectivamente), a partir de 1999 acontece uma grande recuperação desse indicador até 2002. De 2003 em diante, a companhia apresenta uma evolução instável, fechando 2008 com 18,2 interrupções.

A CEAL vem apresentando uma trajetória de recuperação do indicador e o mantendo em níveis baixos, assim como a CELPE, que é a melhor das distribuidoras anali- sadas, mantendo o indicador em torno de 9 interrupções, melhor que a média nacional. A CEMAR a partir de 2000 perdeu o controle do indicador, mas mostra recuperação nos quatro últimos anos. A CEPISA também vem se esforçando para reduzir o FEC, mas não tem alcançado grandes êxitos e se mantém em patamares bastante elevados, comparativamente, sendo a pior de todas as cinco distribuidoras estudadas nesse indicador, em termos absolutos.

Comparando a evolução do FEC médio das distribuidoras nos períodos anterior e posterior ao ano da privatização (e excluindo da análise o ano de 2000), podemos observar por meio da Tabela 8 que a CEAL conseguiu reduzir o indicador no período após 2000 em cerca de $20 \%$, a CEPISA em cerca de $26 \%$ e a CELPE em cerca de $35 \%$. Destaque para a SAELPA, que apresentou redução de $61 \%$, caracterizando-se como a distribuidora de melhor evolução após o ano da privatização. A CEMAR foi a única distribuidora que apresentou aumento na média do indicador no período após 2000 , ou seja, uma piora de aproximadamente $28 \%$, na contramão da tendência apresentada pelas demais distribuidoras.

Assim, para os indicadores financeiros discutidos acima, é possível perceber que a CEAL e a CEPISA (as duas empresas públicas deste estudo) apresentaram as duas piores variações do EBITDA, se compararmos com as demais distribuidoras no período após 2000 (Tabela 2).

Tabela 7 - Evolução do FEC das concessionárias, por ano

\begin{tabular}{|l|l|l|l|l|l|}
\hline \multirow{2}{*}{ ANO } & \multicolumn{7}{|c|}{ FEC (NÚMERO DE INTERRUPÇÕES) } \\
\hline & CEAL & CEPISA & CELPE & CEMAR & SAELPA \\
\hline 1997 & 26.1 & 56.8 & 16.3 & 24.1 & 34.8 \\
\hline 1998 & 23.2 & 50.2 & 13.7 & 18.7 & 59.2 \\
\hline 1999 & 22.7 & 46.8 & 16.4 & 30.6 & 33.9 \\
\hline 2000 & 25.5 & 46.5 & 15.3 & 29.0 & 26.1 \\
\hline 2001 & 21.6 & 31.5 & 14.5 & 40.6 & 14.3 \\
\hline 2003 & 22.7 & 37.8 & 13.6 & 40.4 & 10.9 \\
\hline 2004 & 21.7 & 35.5 & 9.0 & 37.3 & 14.4 \\
\hline 2005 & 18.7 & 41.7 & 9.4 & 39.3 & 14.1 \\
\hline 2006 & 18.5 & 45.0 & 8.0 & 32.9 & 19.9 \\
\hline 2007 & 17.4 & 40.4 & 9.4 & 24.6 & 19.4 \\
\hline 2008 & 17.2 & 36.9 & 8.2 & 19.8 & 20.4 \\
\hline MÉDIA & 15.3 & 36.4 & 8.3 & 16.8 & 18.2 \\
\hline TOTAL & 20.9 & 42.1 & 11.8 & 29.5 & 23.8 \\
\hline
\end{tabular}


Enquanto a CEAL apresentou uma melhora pequena (71\%), a CEPISA apresentou uma trajetória oposta, mostrando uma piora do indicador em $212 \%$, ou seja, uma trajetória bastante pobre, se compararmos com as empresas privatizadas. Da mesma forma, CEAL e CEPISA apresentaram as piores variações no indicador resultado do exercício, no período após 2000 (Tabela 4). Na verdade, as duas empresas públicas tiveram a média deste indicador reduzida drasticamente após 2000, bem diferente da trajetória apresentada pelas empresas privatizadas.

Se considerarmos os indicadores técnicos, é possível observar que a CEAL e a CEPISA apresentam trajetórias compatíveis com as empresas privatizadas e na maioria das vezes foi observada uma trajetória até mais positiva, apesar de, em termos absolutos, a CEPISA apresentar os piores indicadores técnicos de todo o grupo. O DEC é um bom exemplo: CELPE e CEMAR, duas das empresas privatizadas em 2000 , tiveram variações piores do que as duas públicas depois de 2000 (Tabela 6). Na mesma tendência, se considerarmos a média do FEC depois do ano 2000, CEAL e CEPISA apresentaram uma variação melhor do que a privatizada CEMAR, por exemplo (Tabela 8).

\section{DISCUSSÕES}

Inúmeros outros estudos também comparam o desempenho de empresas privadas e públicas no setor de distri-

\section{Gráfico 3 - Evolução do FEC das concessionárias, por ano}

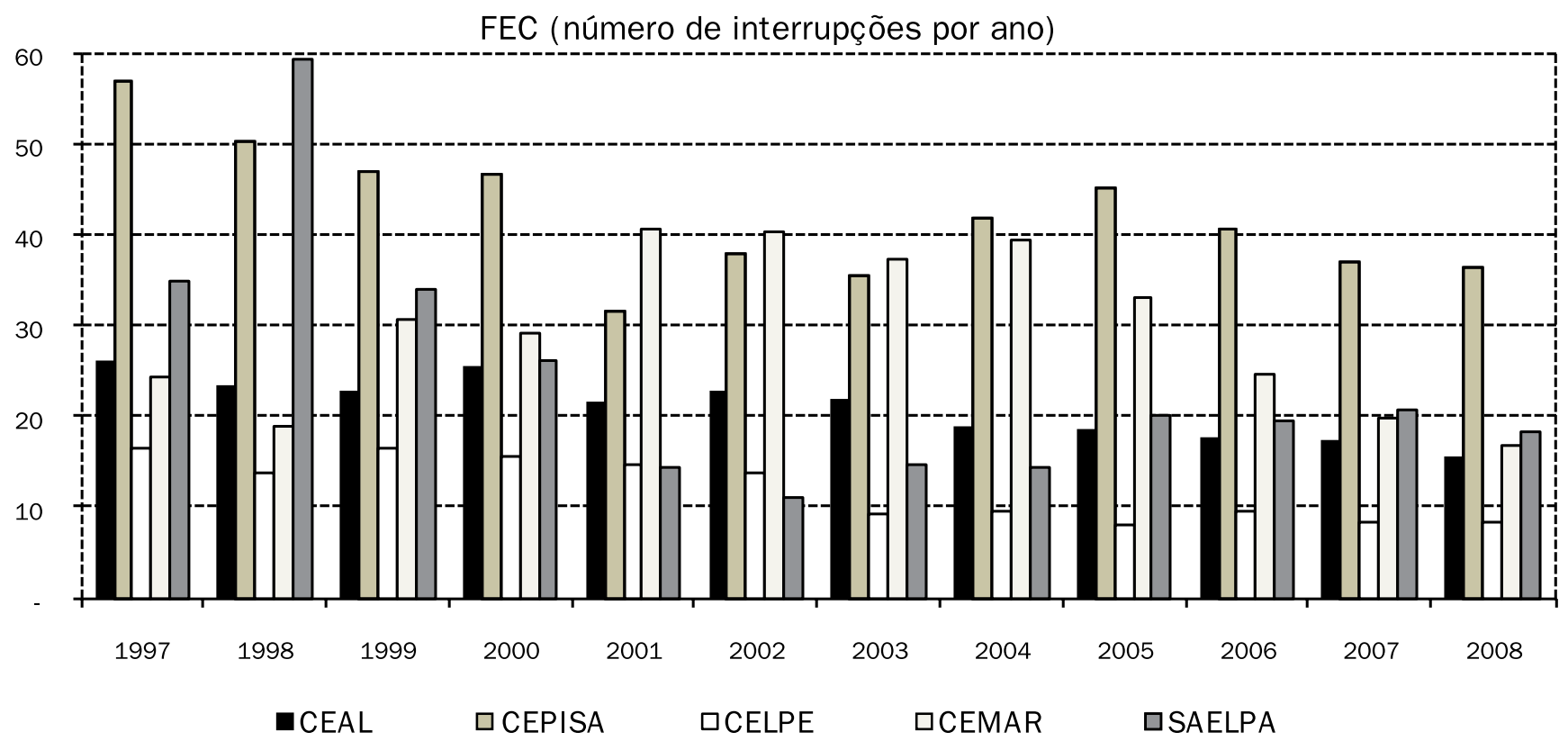

Tabela 8 - Média do FEC das concessionárias, antes e depois de 2000, e variação

\begin{tabular}{|l|c|c|c|}
\hline & MÉDIA DO FEC ANTES E DEPOIS DE 2000 & \\
\hline & ANTES & DEPOIS & VAR \\
\hline CEAL & 24.0 & 19.1 & $-20 \%$ \\
\hline CEPISA & 51.3 & 38.1 & $-26 \%$ \\
\hline CELPE & 15.5 & 10.0 & $-35 \%$ \\
\hline CEMAR & 24.5 & 31.5 & $28 \%$ \\
\hline SAELPA & 42.6 & 16.5 & $-61 \%$ \\
\hline
\end{tabular}


buição de energia elétrica em países desenvolvidos e em desenvolvimento, tais como Atkinson e Halvorsen (1986), Bagdadioglu e outros (1996), Kumbhakar e Hjalmarsson (1998), Schleifer (1998), Megginson e Netter (2001), Berg e outros (2005), entre outros. No Brasil, esta é a primeira vez que se realiza um estudo com múltiplas distribuidoras e múltiplos indicadores, ambos financeiros e técnicos.

Catapan (2005) conclui, com base em testes estatísticos, que não é possível afirmar que o processo de privatização tenha apresentado impactos positivos em relação ao retorno dos acionistas e à solvência das empresas de distribuição de energia elétrica. No entanto, o autor estuda apenas empresas privadas em seu estudo, perdendo os benefícios da comparação com empresas ainda públicas. Rocha e outros (2007) afirmam que, ao analisar o período depois do processo de privatização, apenas em 2005 as empresas de distribuição de energia elétrica começaram a se recuperar, apresentando rentabilidades compatíveis com seus custos estimados de capital. No entanto, os próprios autores aconselham a encarar esses resultados com cuidado, na medida em que a rentabilidade no setor também deve considerar outros aspectos não abordados no estudo. Reis e outros (2007) ressaltam observações de 16 empresas de distribuição de energia elétrica privatizadas, afirmando que existem evidências de que elas melhoraram seus indicadores de DEC e FEC. No entanto, nenhum tipo de comparação é realizado com as empresas ainda públicas.

Para Geller e outros (2004), o Brasil tem demonstrado habilidade de adotar e implementar de forma eficiente políticas energéticas inovativas e tecnologias. Dentre essas bem-sucedidas políticas energéticas, podemos ressaltar o bastante conhecido PROALCOOL (Programa Nacional do Álcool ou Etanol) e os esforços para aumentar a eficiência energética e a conservação de energia no âmbito do PROCEL (Programa Nacional de Conservação de Energia Elétrica). É igualmente importante destacar a criação de um centro de pesquisa público exclusivo para o setor de energia elétrica, o CEPEL (Centro de Pesquisas de Energia Elétrica), em 1974 (JANNUZZI, 2003; 2005), o PROCAP (Programa de Capacitação Tecnológica em Sistemas de Exploração para Águas Profundas), para acumulação tecnológica no setor de petróleo e gás natural (SILVESTRE e DALCOL, 2007; 2008) e mais recentemente o lançamento do tão aguardado Programa do Biodiesel (HALL e outros, 2009). Todas essas políticas fazem parte de um planejamento de longo prazo e um compromisso do Governo Federal Brasileiro com o setor de energia e um engajamento ativo do setor privado, em conjunto com a existência de um bem estruturado conjunto setorial de políticas públicas, o que levou o Brasil à condição de país energeticamente autossuficiente em 2006 (SILVESTRE e DALCOL, 2009).

$\mathrm{Na}$ realidade, motivadas pelas metas de DEC e FEC impostas pela ANEEL para todas as distribuidoras, é possível observar que existe uma tendência de melhora natural e gradual, mesmo observando o sistema de pricecap adotado, o qual pode consistir em uma barreira para a melhoria mais intensa da qualidade do serviço prestado pelas distribuidoras. No contexto atual, as distribuidoras não percebem benefícios em superar as metas impostas pela ANEEL, uma vez que nenhuma recompensa é observada pelas distribuidoras e a regulação é baseada apenas em penalidades para aquelas empresas que não atingirem as metas (REIS e outros, 2007). Políticas de incentivo foram comprovadamente mais eficientes em vários países (GIANNAKIS e outros, 2005), sendo preferíveis às abordagens baseadas apenas no custo, e deveriam ser adotadas no caso Brasileiro. Por essas razões, os indicadores de qualidade das distribuidoras brasileiras poderiam melhorar mais rapidamente do que o observado se uma política de incentivo fosse desenvolvida. A importância de incentivos para a melhoria da qualidade do serviço é apontada como ferramenta fundamental para a melhoria do sistema em sua totalidade, ainda mais no setor de distribuição (JAMASB e POLLITT, 2007; SILVA e outros, 2007; REICHL e outros, 2008), sendo, no entanto, uma política muito particular de país para país, e dependente do modelo adotado (AJODHIA e outros, 2006).

Por princípio, as empresas privadas seguem uma lógica particular: primeiramente, elas objetivam maximizar seus lucros por meio de eficiência operacional e aumento da produtividade, enquanto as empresas de distribuição públicas geralmente não estão preocupadas com questões como dividendos e geração de recursos para os acionistas, mas principalmente com o benefício público em geral (ARNHOLD, 2006). Por outro lado, as empresas públicas sofrem com a instabilidade e descontinuidade política nas esferas federal e estadual, o que gera transtornos e inconsistências na tomada de decisão dessas distribuidoras.

Cabe ressaltar que o modelo setorial atual também não oferece incentivos para a melhoria dos indicadores financeiros das distribuidoras públicas e ações positivas, tais como redução de desperdícios, redução de custos e da inadimplência, o que poderia definitivamente trazer enormes benefícios para essas companhias. Atualmente, toda a ineficiência apresentada pelas distribuidoras públicas é repassada para o consumidor em forma de aumentos tarifários. Quando isso não ocorre (por causa da desaprovação da ANEEL), a ELETROBRÁS é a válvula de 
escape para a cobertura de todos os déficits financeiros dessas empresas por meio de transferência de recursos, prejudicando assim o acionista da ELETROBRÁS, todo o setor elétrico brasileiro (na medida em que esses recursos poderiam ser investidos em melhorias no sistema, como novas usinas, linhas de transmissão ou em outros projetos importantes para o setor) e também a população consumidora em geral.

Além disso, é discutível que as empresas de distribuição de energia elétrica, permanecendo sob o controle de gestão da ELETROBRÁS, sejam a melhor alternativa. Essa estratégia não mostra evidência de ser sustentável nem de ter sucesso, na medida em que os negócios-foco da ELETROBRÁS consistem na atuação direta nos setores de geração e transmissão de energia elétrica, incluindo a operação dos fundos setoriais, e não na distribuição especificamente. Em linha com a análise realizada por Carregaro (2003), a ELETROBRÁS vem apresentando dificuldades para operar de forma direta tantas distribuidoras, ainda mais aquelas que têm apresentado complicações históricas e interferências políticas em suas áreas de concessão (altos níveis de inadimplência e furto de energia sem ações efetivas para melhorias, favorecimentos políticos, liminares e outras variáveis externas ao contexto operacional dessas empresas). Nesse caso, seria preferível contar com um parceiro privado para controlar e gerir essas distribuidoras (a exemplo dos casos da CELPE, CEMAR e SAELPA, nas quais a ELETROBRÁS ainda é acionista minoritário). Com base nesse raciocínio, outra alternativa seria a criação de uma empresa específica para operar e gerir as distribuidoras públicas de energia elétrica ou mesmo a venda de parte dessas companhias para um parceiro privado, com o objetivo de ganhar eficiência em suas operações, isolar a influência política e deixar a ELETROBRÁS operar e expandir suas atividades principais, de geração e transmissão de energia elétrica, no Brasil e no exterior. Na realidade, esta é a verdadeira razão para a qual a ELETROBRÁS foi criada e essas atividades por si só já demandam um grande esforço e planejamento de longo prazo, assim como intensa conexão e coordenação com o Governo Federal Brasileiro e demais parceiros.

Com base na análise apresentada, em relação à evolução do EBITDA e do Resultado do Exercício das distribuidoras estudadas, pôde-se observar um descasamento entre a evolução das distribuidoras privatizadas e das distribuidoras públicas. As distribuidoras privatizadas apresentaram um desempenho muito superior em relação a esses índices, observando um significativo aumento na capacidade de geração de recursos por meio das atividades operacionais, assim como em relação à sua lucratividade geral.
A melhora observada para as empresas privatizadas foi possível graças à diminuição das perdas e furto de energia, diminuição da inadimplência e realização de ajustes nas práticas gerenciais (ou seja, mudanças nos modelos de governança). Todas as três empresas privatizadas mostraram uma evolução surpreendente nos indicadores financeiros após o processo de privatização (Tabelas 2 e 4), enquanto as empresas de distribuição de energia elétrica federais apresentaram um desempenho bastante modesto e algumas vezes até mesmo negativo. Nesse sentido, existem evidências de que a privatização tenha impactado a melhoria do desempenho financeiro das distribuidoras e o retorno financeiro aos acionistas, podendo-se aceitar a Proposição $1(\mathrm{P} 1)$.

No entanto, os índices DEC e FEC melhoraram para todas as distribuidoras contempladas neste estudo (exceto a CEMAR, que apresentou piora na qualidade do serviço prestado após a privatização), principalmente se compararmos com as médias antes e depois da privatização (Tabelas 6 e 8). Essa tendência pode ser confirmada pelo fato de as distribuidoras públicas não apresentarem a pior evolução nos indicadores técnicos, apesar de os resultados da CEPISA não serem suficientes. Em linhas gerais, se a qualidade do serviço prestado pelas distribuidoras privatizadas não evoluiu mais positivamente do que para as empresas públicas, também não é possível observar uma deterioração da qualidade do serviço prestado pelas distribuidoras privadas, como observado no setor de distribuição de energia elétrica italiano por Fumagalli e outros (2007). Consequentemente, nenhuma evidência foi observada de que a privatização tenha beneficiado o desempenho técnico das distribuidoras e a qualidade do serviço prestado aos consumidores, podendo-se portanto rejeitar a Proposição 2 (P2).

\section{CONSIDERAÇÕES FINAIS}

Este trabalho procura analisar indicadores financeiros e técnicos, como forma de verificar o desempenho das empresas de distribuição do setor elétrico brasileiro, especialmente nos períodos imediatamente anterior e posterior às privatizações. Busca interpretar os resultados dos indicadores financeiros e técnicos de empresas que passaram para o capital privado e empresas federais de distribuição do Nordeste do Brasil a fim de promover maior compreensão do processo de privatização do setor elétrico brasileiro e seus efeitos nas distribuidoras de energia elétrica. Este artigo contribui para o melhor entendimento e aprofundamento do debate travado entre políticos, acadêmicos, 
investidores e o povo em geral sobre as vantagens e desvantagens da privatização, trazendo evidências claras do setor de distribuição de energia elétrica. Mediante nossa observação direta do setor na última década, seu cotidiano, mudanças e principalmente com base nos dados apresentados neste trabalho, o processo de privatização foi benéfico para a melhoria do aspecto financeiro, isto é, da perspectiva do acionista. No entanto, não é possível afirmar o mesmo em relação aos aspectos técnicos (qualidade do serviço prestado), isto é, da perspectiva do consumidor, o processo de privatização não gerou melhoria significativas. Esta é a grande contribuição deste artigo, subsidiando profissionais das agências reguladoras e políticos com uma visão mais adequada dos impactos da privatização no setor de distribuição de energia elétrica, provendo assim informações importantes para realização de ajustes e redirecionamentos na política setorial, com o objetivo de melhorar o contexto geral da indústria.

Este estudo apresenta a limitação de estar direcionado para um número reduzido de distribuidoras em uma única região do país. Além disso, acredita-se que a ampliação do número de anos analisados anteriormente à privatização e do número de indicadores, tanto técnicos quanto financeiros, poderia contribuir para uma análise mais ampla do setor de distribuição de energia elétrica no Brasil. Vale ressaltar que esses pontos destacados como limitações deste estudo são factíveis de serem implementados, bem como a inclusão de indicadores sociais e ambientais em estudos de sustentabilidade das distribuidoras, que conjuntamente determinam a nossa agenda para pesquisas futuras.

\section{REFERÊNCIAS}

ASSOCIAÇÃO BRASILEIRA DE DISTRIBUIDORES DE ENERGIA ELÉTRICA.Disponível em: http://abradee.org.br. Acesso em 28.11. 2009.

AJODHIA, V; SCHIAVO, L; MALAMAN, R. Quality regulation of electricity distribution in Italy: an evaluation study. Energy Policy, v. 34 (13), p. 1478-1486, 2006.

AGÊNCIA NACIONAL DE ENERGIA ELÉTRICA. Disponível em: http:// www.aneel.gov.br. Acesso em 28.11.2009.

ARNHOLD, K. Ponto de vista - PPPs e a expansão do setor elétrico. Boletim Olhar Virtual. Rio de Janeiro: Coordenação de Comunicação da UFRJ, ed. 144, dez. 2006.

ASSAF NETO, A. Estrutura e análise de balanço. 7. ed. São Paulo: Atlas, 2002

ATKINSON. S. E; HALVORSEN, R. The relative efficiency of public and private firms in a regulated environment: The case of US electric utilities. Journal of Public Economics, v. 29, n. 3, p. 281-294, 1986.
BAGDADIOGLU, N; PRICE, C. M. W; WEYMAN-JONES, T. G. Efficiency and ownership in electricity distribution: a non-parametric model of the Turkish experience. Energy Economics, v. 18, n. 1/2, p. 1-23, 1996.

BAHIENSE, D. A. Reestruturação e descentralização do setor elétrico brasileiro: o novo modelo institucional. Bahia: Superintendência de Estudos Econômicos e Sociais da Bahia, maio 2005.

BERG, S; LIN, C; TSAPLIN, V. Regulation of state-owned and privatized utilities: Ukraine Electricity Distribution Company performance. Journal of Regulatory Economics, v. 28, n. 3, p. 259-287, 2005.

BILLINTON, R; ALI, S; WACKER, G. Rural distribution system reliability worth evaluation using individual customer outage cost characteristics. Electrical Power and Energy Systems, v. 26, n. 4, p. 235-240, 2004

BILLINTON, R; BILLINTON, J. E. Distribution Systems Reliability Indices IEEE Transactions on Power Delivery, v. 4, n. 1, p. 561-568, 1989

BANCO NACIONAL DE DESENVOLVIMENTO. O setor elétrico - desempenho de 93/99. Informe Infra-Estrutura, n. 53, dez. 2000

BANCO NACIONAL DE DESENVOLVIMENTO. Disponível em: http:// www.bndes.gov.br. Acesso em 28.11.2009.

CATAPAN, E. A. A privatização do setor elétrico brasileiro: os reflexos na rentabilidade e solvência das empresas distribuidoras de energia. Tese de Doutorado em Engenharia de Produção, Programa de Pós-Graduação em Engenharia de Produção da Universidade Federal de Santa Catarina, Florianópolis, 2005.

CARNEIRO, R. Desenvolvimento em crise: a economia brasileira no último quarto do século XX. São Paulo: Editora Unesp/Unicamp, 2002.

CARREGARO, J. C. Proposta de indicadores de desempenho às distribuidoras de energia federalizadas do setor elétrico brasileiro. Dissertação de Mestrado em Engenharia de Produção, Programa de Pós-Graduação em Engenharia de Produção da Universidade Federal de Santa Catarina, Florianópolis, 2003

CAVALIERE, C; LARSEN, E. R; DYNER, I. The privatization of EEB: from cash drain to major contributor. Energy Policy, v. 35, n. 3, p. 1884-1895, 2007.

COMPANHIA ENERGÉTICA DE ALAGOAS. Disponível em: http://www. ceal.com.br. Acesso em 28.11.2009.

COMPANHIA ENERGÉTICA DE PERNAMBUCO. Disponível em: http:// www.celpe.com.br. Acesso em 28.11.2009.

COMPANHIA ENERGÉTICA DO MARANHÃO. Disponível em: http:// www. cemar-ma.com.br. Acesso em 28.11.2009.

COMPANHIA ENERGÉTICA DO PIAUÍ. Disponível em: http://www.cepisa.com.br. Acesso em 28.11.2009.

CHIRARATTANANON, S; NIRUKKANAPORN, S. Deregulation of ESI and privatization of state electric utilities in Thailand. Energy Policy, v. 34, n. 16, p. 2521-2531, 2006. 
CHOWDHURY, A. A; KOVAL, D. O. Current practices and customer value-based distribution system reliability planning. IEEE Transactions on Industry Applications, v. 40, n. 5, p. 1174-1182, 2004.

CHOWDHURY, A. A; AGARWAL, S. K; KOVAL, D. O. Reliability modeling of distributed generation in conventional distribution systems planning and analysis. IEEE Transactions on Industry Applications, v. 39, n. 5, p. $1493-1498,2003$

COHEN, C; LENZEN, M; SCHAEFFER, R. Energy requirements of households in Brazil. Energy Policy, v. 33, n. 4, p. 555-562, 2005.

COMISSÃO DE VALORES MOBILIÁRIOS. Disponível em: http://www. cvm.gov.br. Acesso em 28.11.2009.

CENTRAIS ELÉTRICAS BRASILEIRAS. Disponível em: http://www. eletrobras.com.br. Acesso em 28.11.2009.

ERDOGDU, E. Regulatory reform in Turkish energy industry: an analysis. Energy Policy, v. 35, n. 2, p. 984-993, 2007.

ESPOSITO, A. S. Privatização da Light: a repartição dos ganhos de produtividade. Trabalho de Conclusão de Curso de Graduação em Economia, Centro de Ciências Jurídicas e Econômicas, Universidade Federal do Rio de Janeiro, Rio de Janeiro, 2000.

FINANCIADORA DE ESTUDOS E PROJETOS. Termos e conceitos. Rio de Janeiro: FINEP, 2002.

FOCACCI, A. Empirical analysis of the environmental and energy policies in some developing countries using widely employed macroeconomic indicators: the cases of Brazil, China and India. Energy Policy, v. 33, n. 4, p. $543-554,2005$.

FUMAGALLI, E; GARRONE, P; GRILLI, L. Service quality in the electricity industry: the role of privatization and managerial behavior. Energy Policy, v. 35, n. 12, p. 6212-6224, 2007.

GABRIELE, A. Policy alternatives in reforming energy utilities in developing countries. Energy Policy, v. 32, n. 11, p. 1319-1337, 2004.

GEISLER, E. The metrics of science and technology. Connecticut: Quorum, 2000 .

GELLER, H; SCHAEFFER, R; SZKLO, A; TOLMASQUIM, M. Policies for advancing energy efficiency and renewable energy use in Brazil. Energy Policy, v. 32, n. 12, p. 1437-1450, 2004.

GHISI, E; GOSCH, S; LAMBERTS, R. Electricity end-uses in the residential sector of Brazil. Energy Policy, v. 35, n. 12, p. 4107-4120, 2007.

GIANNAKIS, D; JAMASB, T; POLLITT, M. Benchmarking and incentive regulation of quality of service: an application to the UK electricity distribution networks. Energy Policy, v. 33, n. 17, p. 2256-2271, 2005.

GOEL, L; BILLINTON, R. Evaluation of interrupted energy assessment rates in distribution systems. IEEE Transactions on Power Delivery, v. 6, n. 4, p. 1876-1882, 1991.

GOMES, A. C. S; ABARCA, C. D. G; FARIA, E. A. S. T; FERNANDES, H. H. O. BNDES 50 anos - histórias setoriais: o setor elétrico. Rio de Janeiro: BNDES, 2002.
HALL, J; MATOS, S; SEVERINO, L; BELTRÃO, N. Brazilian biofuels and social exclusion: established and concentrated ethanol versus emerging and dispersed biodiesel. Journal of Cleaner Production, v. 17, Sup. 1, p. S77-S85, 2009.

HAMILTON, B. EBITDA: still crucial to credit analysis. Commercial Lending Review, September Issue, p. 47-48, 2003.

IBGE - Instituto Brasileiro de Geografia e Estatística. Contas Regionais do Brasil 2006. IBGE, 2007.

IBGE - Instituto Brasileiro de Geografia e Estatística. Disponível em: http:// www.ibge.gov.br. Acesso em 28.11.2009.

ICÓ, J; BRAGA, R. P. EBITDA: lucro ajustado para fins de avaliação de desempenho operacional. Revista Contabilidade e Informação: Conhecimento e Aprendizagem, v. 3, n. 8, p. 39-47, 2001.

ISO - International Organization for Standardization. Information and documentation - performance indicators for electronic library services. Genebra: ISO/TR 20983:2003(E), 2003.

JAMASB, T; POLLITT, M. Incentive regulation of electricity distribution networks: lessons of experience from Britain. Energy Policy, v. 35, n. 12, p. $6163-6187,2007$.

JANNUZZI, G. M. Uma avaliação das atividades recentes de PED em energia renovável no Brasil e reflexões para o futuro. Campinas: Energy Discussion Paper no 2.64-01/03, 2003.

JANNUZZI, G. M. Power sector reforms in Brazil and its impacts on energy efficiency and research and development activities. Energy Policy, v. 33, n. 13, p. 1753-1762, 2005.

KALAY, A; SINGHAL, R; TASHJIAN, E. Is Chapter 11 costly? Journal of Financial Economics, v. 84, n. 3, p. 772-796, 2007.

KING, M. R; SEGAL, D. Market segmentation and equity valuation: comparing Canada and the United States. Journal of International Financial Markets, Institutions \& Money, v. 18, n. 3, p. 245-258, 2008.

KUMBHAKAR, S. C; HJALMARSSON, L. Relative performance of public and private ownership under yardstick competition: electricity retail distribution. European Economic Review, v. 42, n. 1, p. 97-122, 1998.

LaCOMMARE, K. H; ETO, J. H. Cost of power interruptions to electricity consumers in the United States (US). Energy, v. 31, n. 12, p. $1845-$ 1855, 2006.

MARTINS, E. EBITDA: o que é isso? Temática Contábil e Balanços IOB, v. 6, n. 19, p. 01-07, 1998 .

MEGGINSON, W. L; NETTER, J. M. From state to market: a survey of empirical studies on privatization. Journal of Economic Literature, v. 39, n. 2, p. 321-389, 2001.

MENDEZ, C. A. B. EBITDA, es um indicador financiero contable de agregacion de valor? Capiv Review, v. 5, n. 1, p. 41-54, 2007. 
BRUNO DOS SANTOS SILVESTRE - JEREMY HALL · STELVIA MATOS LUIZ AUGUSTO PEREIRA DE ANDRADE FIGUEIRA

MENDONÇA, A. F; DAHL, C. The Brazilian electrical system reform. Energy Policy, v. 27, n. 2, p. 73-83, 1999.

OECD, Organization for Economic Co-operation and Development. Glossary of statistical terms. Genebra: OCDE, 2001.

PARKER, D; KIRKPATRICK, C. Privatisation in developing countries: a review of the evidence and the policy lessons. Journal of Development Studies, v. 41, n. 4 , p. 513-541, 2005.

PIRES, J. C. L. Desafios da reestruturação do setor elétrico brasileiro. Rio de Janeiro: BNDES, Texto para Discussão n. 76, mar. 2000.

REICHL, J; KOLLMANN, A; TICHLER, R; SCHNEIDER, F. The importance of incorporating reliability of supply criteria in a regulatory system of electricity distribution: an empirical analysis for Austria. Energy Policy, v. 36, n. 10, p. 3862-3871, 2008.

REIS, R. M. M; TEIXEIRA, A. C. C.; PIRES, M. A Os benefícios da privatização: evidência no setor elétrico brasileiro. Revista de Contabilidade e Organizações, v. 1, n. 1, p. 56-70, 2007.

RIDALVO, M. A. O. Impacto do racionamento nos resultados das empresas concessionárias do serviço público de distribuição de energia elétrica: um estudo nas empresas privadas da região Nordeste. Dissertação de Mestrado em Ciências Contábeis, Pró-Reitoria de Pós-Graduação, Universidade Federal do Rio Grande do Norte, Natal, 2003.

ROCHA, K; CAMACHO, F; BRAGANÇA, G. Return on capital of Brazilian electricity distributors: a comparative analysis. Energy Policy, v. 35, n. 4, p. $2526-2537,2007$

ROZADOS, H. B. S. Uso de indicadores na gestão de recursos de informação. Revista Digital de Biblioteconomia e Ciência da Informação, v. 3, n. 1, p. 60-76, 2005.

SAELPA - Sociedade Anônima de Eletrificação da Paraíba - Disponível em: http://www.saelpa.com.br. Acesso em 28.11.2008.

SALGADO, L. H. Agências regulatórias na experiência brasileira: um panorama do atual desenho institucional. Brasília: IPEA, Texto para Discussão, n. 941, 2003.

SANTANA, L; LIMA, F. G. EBITDA: uma análise de correlação com os retornos totais aos acionistas no mercado de capitais brasileiro. In: Congresso DA Univesidade de são paulo de Controladoria e Contabilidade, 44, 2004, São Paulo, Anais. São Paulo, 2004.

SÉRIES ECONÔMICO-FINANCEIRAS das empresas do setor de energia elétrica. ELETROBRÁS e UFRJ, Rio de Janeiro, 1999.

SÉRIES ECONÔMICO-FINANCEIRAS das empresas do setor de energia elétrica. Rio de Janeiro: ELETROBRÁS e UFRJ, 2000.

SÉRIES ECONÔMICO-FINANCEIRAS das empresas do setor de energia elétrica. Rio de Janeiro: ELETROBRÁS e UFRJ, 2001.

SÉRIES ECONÔMICO-FINANCEIRAS das empresas do setor de energia elétrica. Rio de Janeiro: ELETROBRÁS e UFRJ, 2005.
SÉRIES ECONÔMICO-FINANCEIRAS das empresas do setor de energia elétrica. Rio de Janeiro: ELETROBRÁS e UFRJ, 2005.

SCHLEIFER, A. State versus private ownership. Journal of Economic Perspectives, v. 12, n. 4, p. 133-150, 1998.

SILVA, M. G; RODRIGUES, A. B; CASTRO, C. L. C; NETO, A. C; MOUTINHO, E. A; NETO, N. S. A; CAVALCANTE, A. B. An application of predictive reliability analysis techniques in Brazil's northeast distribution networks. Electrical Power and Energy Systems, v. 29, N. 2, p. 155-162, 2007.

SILVESTRE, B; DALCOL, P. Conexões de conhecimento e posturas tecnológicas das firmas: evidências da aglomeração industrial de petróleo e gás da Bacia de Campos. Gestão \& Produção, v. 14, n. 2, p. 221-238, 2007.

SILVESTRE, B; DALCOL, P. Aglomeração industrial de petróleo e gás da região produtora da Bacia de Campos: sistema de conhecimento, mudanças tecnológicas e inovação. RAUSP - Revista de Administração da Universidade de São Paulo, v. 43, n. 1, p. 84-96, 2008.

SILVESTRE, B; DALCOL, P. Geographical proximity and innovation: evidences from the Campos Basin oil \& gas industrial agglomeration - Brazil . Technovation, v. 29, n. 8, p. 546-561, 2009.

TOLMASQUIM, M. T; COHEN, C; SZKLO, A. CO2 emissions in the Brazilian industrial sector according to the integrated energy planning model (IEPM). Energy Policy, v. 29, n. 8, p. 641-651, 2001.

TREJO-PECH, C. O; WELDON, R; HOUSE, L; SALAS-GUTIERREZ, T. Accruals, free cash flows, and EBITDA for agribusiness. In: America Agricultural Economics Association Annual Meeting, 2006, California Anais. Califórnia, 2006.

VASCONCELOS, Y. L. EBITDA: como instrumento de avaliação de empresas. Revista Brasileira de Contabilidade, v. 31, n. 1, p. 39-47, 2002.

VASCONCELOS, Y. L. EBITDA - Retrato do desempenho operacional Informações Objetivas - IOB - COMENTA, v. 49, n. 1, p. 1-6, 200la.

VASCONCELOS, Y. L. EBITDA - Redescoberta do potencial informativo dos indicadores absolutos. Revista do Conselho Regional do Rio Grande do Sul, n. 102, dez. 2001b.

WARREN, C. A; PEARSON, D. J; SHEEHAN, M. T. A nationwide survey of recorded information used for calculating distribution reliability indices. IEEE Transactions on Power Delivery, v. 18, n. 2, p. 449-453, 2003.

WERNECK, R. L. F. Privatizações do setor elétrico: especificidade do caso brasileiro. Rio de Janeiro: Departamento de Economia - PUC-Rio, Texto para discussão, n. 373, maio 1997.

WILLIAMS, G; ROBINSON, A. R. The energy policy act's reliability provisions: uncontroversial, yes, but doomed to ineffectiveness? The Electricity Journal, v. 19, n. 1, p. 10-17, 2006. 